\title{
Colonization patterns of the invasive Brazilian peppertree, Schinus terebinthifolius, in Florida
}

\author{
DA Williams ${ }^{1}$, E Muchugu ${ }^{2}$, WA Overholt ${ }^{3}$ and JP Cuda ${ }^{4}$ \\ ${ }^{1}$ Department of Marine Biology and Fisheries, Marine Genomics Laboratory, Rosenstiel School of Marine and Atmospheric Sciences, \\ University of Miami, Miami, FL, USA; ${ }^{2}$ International Centre of Insect Physiology and Ecology (ICIPE), Nairobi, Kenya; ${ }^{3}$ Department of \\ Entomology and Nematology, Institute of Food and Agricultural Sciences, Indian River Research and Education Center, University of \\ Florida, Fort Pierce, FL, USA and ${ }^{4}$ Department of Entomology and Nematology, University of Florida, Gainesville, FL, USA
}

\begin{abstract}
Invasive species are believed to spread through a process of stratified dispersal consisting of short-distance diffusive spread around established foci and human mediated longdistance jumps. Brazilian peppertree (Schinus terebinthifolius), native to South America, was introduced twice as an ornamental plant into Florida, USA, just over 100 years ago. A previous study indicated that these two introductions were from genetically differentiated source populations in the native range. In this study, we took advantage of these contrasting genetic signatures to study the spatial spread of Brazilian peppertree across its entire range in Florida. A combination of spatial genetic and geostatistical analyses using chloroplast and nuclear microsatellite markers revealed evidence for both diffusive dispersal and longdistance jumps. Chloroplast DNA haplotype distributions and extensive bands of intra-specific hybridization revealed extensive dispersal by both introduced populations across
\end{abstract}

the state. The strong genetic signature around the original introduction points, the presence of a general southeast to northwest genetic cline, and evidence for short-distance genetic spatial autocorrelation provided evidence of diffusive dispersal from an advancing front, probably by birds and small mammals. In the northernmost part of the range, there were patches having a high degree of ancestry from each introduction, suggesting long-distance jump dispersal, probably by the movement of humans. The evidence for extensive movement throughout the state suggests that Brazilian peppertree will be capable of rapidly recolonizing areas from which it has been eradicated. Concerted eradication efforts over large areas or the successful establishment of effective biocontrol agents over a wide area will be needed to suppress this species.

Heredity (2007) 98, 284-293. doi:10.1038/sj.hdy.6800936; published online 24 January 2007

Keywords: dispersal; invasive species; range expansion; molecular markers; Schinus terebinthifolius; spatial genetic structure

\section{Introduction}

The spread of colonizing and invasive species often occurs through stratified dispersal, which consists of both local spread around established foci and longdistance jumps (Baker, 1974; Hengeveld, 1989; Novak and Mack, 2001; Suarez et al., 2001). Stratified dispersal greatly increases the rate and distance of range expansion compared to simple diffusion dispersal and has provided an explanation for the rapid northward advancement of tree species in Europe and North America after the last glaciation (Higgins and Richardson, 1999; Petit et al., 2004). The mode of long-distance dispersal for introduced species in their non-native range is often through human transport. The creation of these pioneering patches ahead of the main introduction is expected to facilitate the rapid expansion of invasive species after their initial establishment.

Correspondence: Dr DA Williams, Marine Genomics Laboratory, Rosenstiel School of Marine and Atmospheric Sciences, University of Miami, 4600 Rickenbacker Causeway, Miami, FL, USA.

E-mail: dean.williams@rsmas.miami.edu

Received 7 April 2006; revised 4 September 2006; accepted 23 November 2006; published online 24 January 2007
Understanding the dispersal patterns of invasive species can have important implications for management. For instance, eradication of the small pioneering populations in front of the main invasion front can be the most effective means to slow down or stop the spread of an invasion in its early stages (Moody and Mack, 1988). Invasive species that are capable of long-distance dispersal also may need biocontrol agents that are capable of long-distance dispersal to keep up with their hosts (Fagan et al., 2002). An isolated population of an invasive species could potentially be eradicated at that site (Robertson and Gemmell, 2004); however, species that can rapidly re-colonize areas where they have been eradicated make control efforts more difficult. These situations may necessitate simultaneous eradication across all connected populations (Hampton et al., 2004) or the successful establishment of biocontrol agents over a wide area in order to effectively suppress the invasive species (Fagan et al., 2002).

Modeling the spread of invasions has been an active area of research and yet, empirical estimates of the frequency and extent of dispersal have been very difficult to obtain (Hastings et al., 2005). Molecular genetic methods can provide insight into the movement patterns and modes of dispersal for colonizing species, and in some situations may be the only option for 
estimating those parameters in species for which there has been little or no historical accounting of invasion. In trees and many other plants, the establishment of pioneering colonies occurs through seed dispersal. This process is predicted to result in founder events which leave genetic footprints or patches of maternal lineages that can be detected using maternally inherited genetic markers (Petit et al., 2004). Over time, these patches are predicted to become more diffuse and ultimately disappear due to the homogenizing forces of gene flow. In practice, however, it is often difficult to detect the genetic footprint of these long-distance pioneering events because these populations contain a subset of the genetic makeup present in the source population. When pioneering individuals are from differentiated populations, however, genetic methods are especially powerful at detecting these kinds of dispersal events (Petit et al., 2004). When two previously separated populations with unique histories meet through range expansion, a hybrid zone emerges and the resulting genetic pattern on either side of this zone can provide insight into both diffusion and long-distance dispersal (Johansen and Latta, 2003).

Brazilian peppertree (Schinus terebinthifolius) is a tropical, dioecious tree that is native to Brazil, northeast Argentina, Paraguay, and Uruguay (Ewel, 1986; Ferriter, 1997). Historical records indicate that Brazilian peppertree was introduced twice as an ornamental plant into Florida between ca 1898 and 1900 (Morton, 1978). One introduction occurred in Punta Gorda, on the west coast, while the other introduction occurred in Miami, on the east coast. Genetic analyses of Brazilian peppertree in Florida and South America also indicate that there were two introductions from separate source regions that subsequently hybridized in Florida (Williams et al., 2005). Brazilian peppertree currently occurs throughout the state of Florida south of the frost line and is one of the most difficult to eradicate invasive plants (Ferriter, 1997; Schmitz et al., 1997). It is an efficient colonizer of disturbed sites that are either man-made or natural (e.g., hurricane-damaged areas), and in south Florida alone, Brazilian peppertree has invaded over 280000 ha (Schmitz et al., 1997).

It is likely that both diffusion and long-distance dispersal have played an important role in the spread of Brazilian peppertree in Florida. In the past, humans were probably the main mode of long-distance dispersal (i.e., $\geqslant 50 \mathrm{~km}$ ) by moving seeds and seedlings among towns for planting. The presence of bright red berries, and the fact that ingestion of Brazilian peppertree seeds by birds significantly increases germination rates and subsequent recruitment indicate that Brazilian peppertree is specifically adapted for dispersal by avian frugivores (Panetta and McKee, 1997; Mandon-Dalger et al., 2004). Migrating American robins (Turdus migratorius) and gray catbirds (Dumetella carolinensis) are believed to have dispersed the seeds widely in Florida (Ewel et al., 1982). More localized seed dispersal also occurs by resident northern mockingbirds (Mimus polyglottos) and small mammals such as raccoons (Procyon lotor) and Virginia opossums (Didelphis virginiana) (Ewel et al., 1982; Ewel, 1986; personal observation). Small native flies and wasps are the main pollinators (Ewel et al., 1982). Because these species are resident and do not range over very long distances, presumably most of these dispersal events are less than $5 \mathrm{~km}$.

Although the areas surrounding Punta Gorda and Miami still retain a genetic footprint of the original introductions into Florida (Williams et al., 2005), the pattern of spread and hybridization throughout the rest of the state is unknown. Because there have been multiple opportunities for long-distance dispersal in this species, we expected to see a genetic signal of stratified dispersal across the state, which includes pioneering patches from each introduction and evidence of hybridization between patches as they coalesced (e.g., Nichols and Hewitt, 1994; Ibrahim et al., 1996; Johansen and Latta, 2003). In contrast, if dispersal had been predominately due to an 'advancing front', then we would expect to see evidence of a well-defined hybrid zone where the two introductions come together (e.g., Nichols and Hewitt, 1994; Ibrahim et al., 1996). In this study, we used a combination of geostatistical and spatial genetic analyses to examine the current spatial genetic pattern of Brazilian peppertree across the entire species' range in Florida. We specifically asked (1) what is the spatial genetic distribution of Brazilian peppertree in Florida and does it support the two proposed introduction sites? (2) what is the pattern of hybridization across the state?, and (3) do we see genetic evidence for stratified dispersal with noteworthy long-distance pioneering events?

\section{Methods}

The individuals analyzed in this study include 354 individuals previously sampled by Williams et al. (2005), as well as an additional set of 238 individuals that were collected from previously unsampled areas in the central and western parts of the state as well as from Miami-Dade County (Figure 1). We collected more individuals from Miami-Dade County to improve our ability to characterize genetic structure at a fine spatial scale. Global Positioning System (GPS) coordinates were recorded for all individuals. The accuracy of our GPS coordinates was expected to be $\pm 7 \mathrm{~m}$; however, the spatial scales at which we conducted our analyses were well above this degree of error and so it was not expected to impact our results.

We genotyped all sampled individuals at five nuclear microsatellite loci and an intergenic region in the chloroplast DNA (cpDNA) (trnS and trnG; Hamilton, 1999) as described in Williams et al. (2002) and Williams et al. (2005). Genotypes were scored using an ABI 310 Genetic Analyzer and GENEMAPPER 3.0 (PE Biosystems, Foster City, CA, USA). Previous results revealed that there were two separate introductions into Florida which are distinguished by two unique cpDNA haplotypes that differ by three substitutions and can easily be distinguished by a microsatellite region that consists of 11 single-nucleotide repeats in one haplotype and 14 repeats in the other. In this paper, these haplotypes are referred to as 'eastern' from Miami and 'western' from Punta Gorda which correspond to haplotypes B and A, respectively, in Williams et al. (2005).

We used a Bayesian clustering method implemented in the program STRUCTURE version 2.1 to estimate the degree of hybridization between the two introductions into Florida (Pritchard et al., 2000; Pritchard and Wen, 2003). The membership of each individual in a sub- 


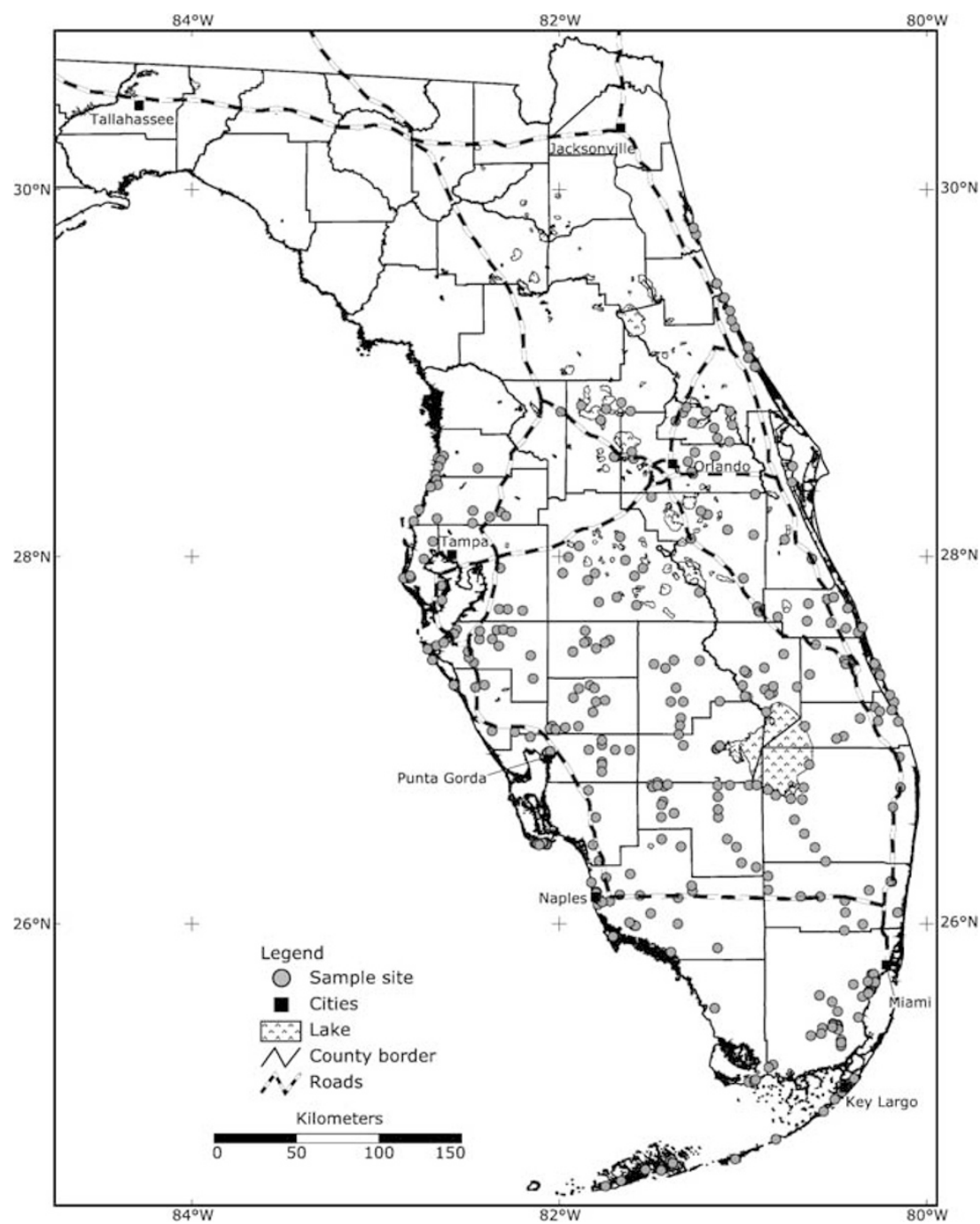

Figure 1 Sampling locations (closed circles) of Brazilian peppertree plants in Florida, USA.

population (eastern or western) was estimated as $(q)$, the ancestry coefficient, which varies on a scale from 0 to 1.0, with 1.0 indicating full membership in a population. Individuals could be assigned to multiple clusters (with values of $q$ summing to 1.0) indicating they are admixed. We first ran the Monte Carlo Markov Chain (MCMC) for $10^{6}$ iterations following a burn-in period of $10^{5}$ iterations for $K=1-10$ using the correlated allele frequencies model and assuming admixture (the default values) to determine if inclusion of the new samples changed our previous results. This analysis revealed that the most likely number of introductions was still two and the $q$ values were very similar for individuals analyzed previously $\left(y=0.97 x+0.001, R^{2}=0.996\right)$. In addition, a $t$-test was used to compare the average level of east ancestry coefficient (arcsine transformed) between the eastern and western cpDNA haplotypes to test the concordance of the nuclear and cpDNA markers.

We determined the distance from each sampled individual to the original introduction cities (Miami and Punta Gorda) and grouped them into distance classes. We then plotted the proportion of the respective haplotype (eastern for distances from Miami and western for distances from Punta Gorda) that occurred in each distance class. We only included data points that had more than 10 individuals to more accurately calculate proportions. This resulted in omitting the furthest distance classes for each introduction $(300-350 \mathrm{~km}$ for Punta Gorda and $425-475 \mathrm{~km}$ for Miami). Although this measure does not provide an estimate of the actual dispersal distances moved by individual seeds, it does provide insight into the extent of dispersal by each haplotype since introduction.

\section{Spatial autocorrelation}

We analyzed the relationship between individual pairwise genetic similarity and geographic distance using the spatial autocorrelation method in GenAlEx6 (Peakall and Smouse, 2005). This method uses a multilocus genetic distance measure (phiPT, Smouse and Peakall, 1999) that strengthens the spatial signal by reducing locus to locus and allele to allele variability. The autocorrelation coefficient, $r$, is a measure of the genetic similarity between individuals that fall within a defined distance class. The significance of $r$ is determined by random permutation of all individuals among distance classes and recalculating $r 1000$ times to set the upper and lower 
95\% confidence limits around this value. If the $r$ value fell above or below these limits, then significant spatial structure was inferred. Ninety-five percent confidence intervals were also calculated around each $r$ value by bootstrapping $r$ values within each distance class 1000 times. If these $95 \%$ confidence values did not include $r=0$, then significant spatial structure was inferred. These values also provided a graphical test of significance among $r$ values in different distance classes.

\section{Geostatistical models}

To visualize the pattern of hybridization and dispersal across Florida by the original two introductions, we used 'kriging' - a method for interpolating the values of a variable over the geographic area from which the sample was taken by incorporating a semivariogram model for spatial correlation for the cpDNA haplotypes and the eastern ancestry coefficient $(q)$ calculated from the multilocus nuclear microsatellite genotypes. At some localities, a single GPS coordinate was recorded even though several samples were collected from 10 to $50 \mathrm{~m}$ apart. In these instances, we simply averaged across individuals so that only a single data point was associated with each coordinate in the variogram model and subsequent interpolation.

Geostatistical analyses consist of describing and modeling the variogram as a function of distance. The variogram measures the semivariance of the difference between points separated by a given distance $h$ in space. The empirical variogram is estimated from data as a discrete function of given distance classes by $\gamma(h)=$ $(1 / 2 N(h)) \sum\left(z_{i}-z_{i}+h\right)^{2}$, where $\gamma(h)=$ semivariance for interval distance class $h, q_{i}=$ measured sample value at point $i, q_{i}+h=$ measured sample value at point $i+h$, and $N(h)=$ total number of sample couples for the lag interval $h$. The variogram may be calculated for all directions in space, or for specific directions to test for anisotropy (direction-dependent trend in the data). In the latter case, only the pairs of points connected along a given direction in space ( \pm tolerance angle) are taken into account in the calculations.

Typically, when variogram values are plotted for all $h$, the values increase with increasing distance, and usually reach a constant value called the sill. The distance at which the sill is attained, called the range, represents the distance beyond which two values may be considered independent. Theoretically, the origin of the variogram is zero, although error associated with fine-scale structure below the smallest distance class or measurement error results in a discontinuity, or nugget effect. The nugget to sill ratio gives an indication of the amount of variance that can be used in the model, with larger values indicating a smaller proportion of the total variance that is available to model spatial dependence.

The empirical variogram may be adjusted to several theoretical models including the exponential, Gaussian, and spherical models. The linear model is used for variograms that do not reach a plateau, and characterizes either clinal patterns or patterns with ranges exceeding the maximum distance considered. Flat variograms, representing the 'pure nugget' effect, characterize random patterns of variation.

In practice, only pairs of points separated by less than half the maximum distance observed are considered when modeling variograms (Le Corre et al., 1998). We therefore calculated variograms for 15 distance classes ranging from 0 to ca $290 \mathrm{~km}$ using the geostatistical package GS $+{ }^{\circledR}$ (Gamma Design Software, Plainwell, MI, USA). Various semivariogram models were evaluated (i.e., spherical, exponential, linear, and Gaussian) to determine which model best fit the spatial structure of each variable. The program used residual sums of squares (RSS) values to choose models and model parameters that minimize RSS. Semivariogram models were also evaluated for the presence of anisotropy (direction-dependent trend in the data), and adjusted accordingly.

Data were then block-kriged using the appropriate semivariogram models to produce interpolated maps with $1 \mathrm{~km}$ grids. Finally, cross-validation analysis was conducted as a means for evaluating alternative models for kriging. In cross-validation analysis, each measured point in a spatial domain was individually removed from the domain and its value estimated via kriging as though it were never present. In this way, a comparison can be made of estimated versus actual values for each sample location in the domain, and coefficients of determination were used to assess goodness of fit. To display the results, kriged values were exported from $\mathrm{GS}+{ }^{\circledR}$ package into the GIS package ArcView ${ }^{\mathrm{TM}}$ software package (Environmental Systems Research Institute, Inc., Redlands, CA, USA). The correlation between the interpolated spatial patterns for the cpDNA haplotypes and eastern ancestry was also calculated using ArcView.

\section{Results}

Of the 592 sampled individuals, 291 (49\%) had the eastern haplotype and $301(51 \%)$ had the western haplotype. The average proportion of ancestry $(q)$ for the two Brazilian peppertree introductions was also evenly split across our samples $(q=0.52$ eastern and 0.48 western). The proportion of east ancestry was significantly higher in individuals that had the eastern haplotype (mean $=0.68 \pm 0.01$ eastern ancestry vs $0.37 \pm 0.02$ western ancestry, $\left.t_{590}=-15.0, P<0.001\right)$. Likewise, the proportion of west ancestry was also significantly higher in individuals that had the western haplotype (mean $=0.63 \pm 0.02$ western ancestry vs $0.32 \pm 0.01$ eastern ancestry, $t_{590}=5.1, P<0.001$ ).

Each haplotype was most common close to its original point of introduction and decreased at increasing distances from the introduction city (Figure 2). Within the range of distances shared between Punta Gorda and Miami $(25-275 \mathrm{~km})$, the decrease with distance was very similar for both haplotypes (western haplotype $y=-0.06 x+0.92, \quad R^{2}=0.61$; eastern haplotype $y=-0.05 x+0.84, R^{2}=0.62$ ). Both haplotypes can also be found at the furthest sampled distance category from each introduction city $(350 \mathrm{~km}$ for Punta Gorda and $475 \mathrm{~km}$ for Miami).

\section{Spatial autocorrelation}

Across the entire state, spatial autocorrelation analyses revealed a clinal pattern of genetic structure at the nuclear microsatellite loci as well as the cpDNA locus (Figures $3 \mathrm{a}$ and b). For the nuclear loci, individuals located within $147 \mathrm{~km}$ of each other were more similar than expected at random, whereas those individuals 


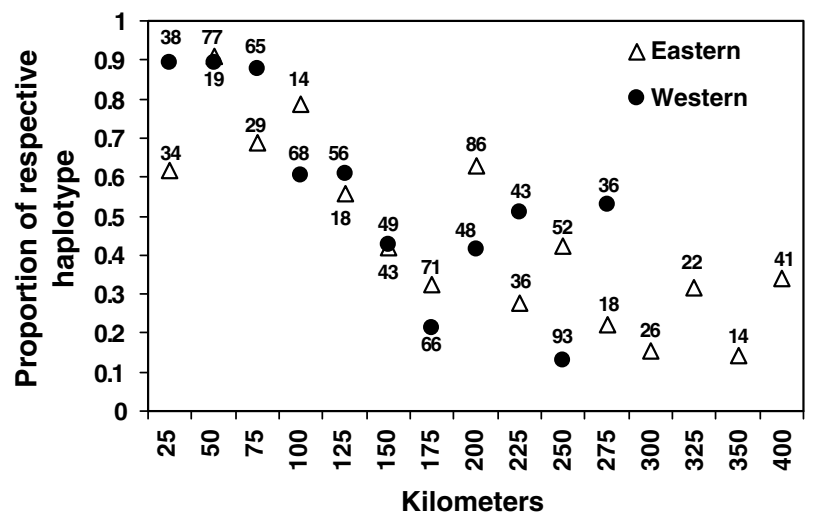

Figure 2 The proportion of Brazilian peppertree chloroplast haplotypes found at increasing distances from their respective introduction points. The eastern haplotype originated in the city of Miami and the western haplotype originated in Punta Gorda. Numbers are total sample sizes for each point.

separated by greater distances were less similar than expected (Figure 3a). Bootstrapped 95\% CIs around $r$ values did not overlap between distance classes for which there was positive spatial structure, providing further evidence that individuals were genetically less similar to each other as geographic distance increased. Each locus-by-locus analysis also revealed a significant clinal pattern of genetic structure, and estimates of genetic patch size (where $r$ crosses 0) ranged from 140 to $150 \mathrm{~km}$. The analysis of the cpDNA locus revealed a slightly more complex spatial structure than the nuclear microsatellite loci; this locus exhibited significant positive autocorrelation up to $133 \mathrm{~km}$ (i.e., its initial genetic patch size), then significant negative autocorrelation before becoming positive again at $270 \mathrm{~km}$ (Figure $3 \mathrm{~b}$ ). As expected, spatial autocorrelation values were higher for the maternally inherited cpDNA locus, which is dispersed solely through seeds.

Spatial autocorrelation, using nuclear microsatellite genotypes, was also investigated at a smaller spatial scale in an area for which we sampled 83 individuals (Miami-Dade County in southeastern Florida), all of which had the eastern haplotype (Figure 4). At this smaller spatial scale, genetic patch size was $\sim 6.6 \mathrm{~km}$ and rather than exhibiting a clinal pattern of genetic structure, the microsatellite loci revealed a pattern more similar to isolation-by-distance with significant positive autocorrelation at the smallest distance category $(5 \mathrm{~km})$ and a random pattern at increasing distance categories (Figure 4). Similarly, in an area of the plant's range that has predominantly high western ancestry (north of $28^{\circ}$ latitude, see below), there was significant positive spatial autocorrelation $(r=0.19, P=0.005)$ only in the first distance class $(5 \mathrm{~km})$, with $r$ then decreasing and remaining within the $95 \% \mathrm{CI}$ out to $250 \mathrm{~km}$.

\section{Geostatistical models}

The Gaussian semivariogram model for spatial correlation best fit the spatial structure of both the eastern and western cpDNA haplotypes (Table 1). The eastern haplotype had a range distance and nugget to sill ratio that were almost half as large as for the western haplotype. This indicates that the eastern haplotype
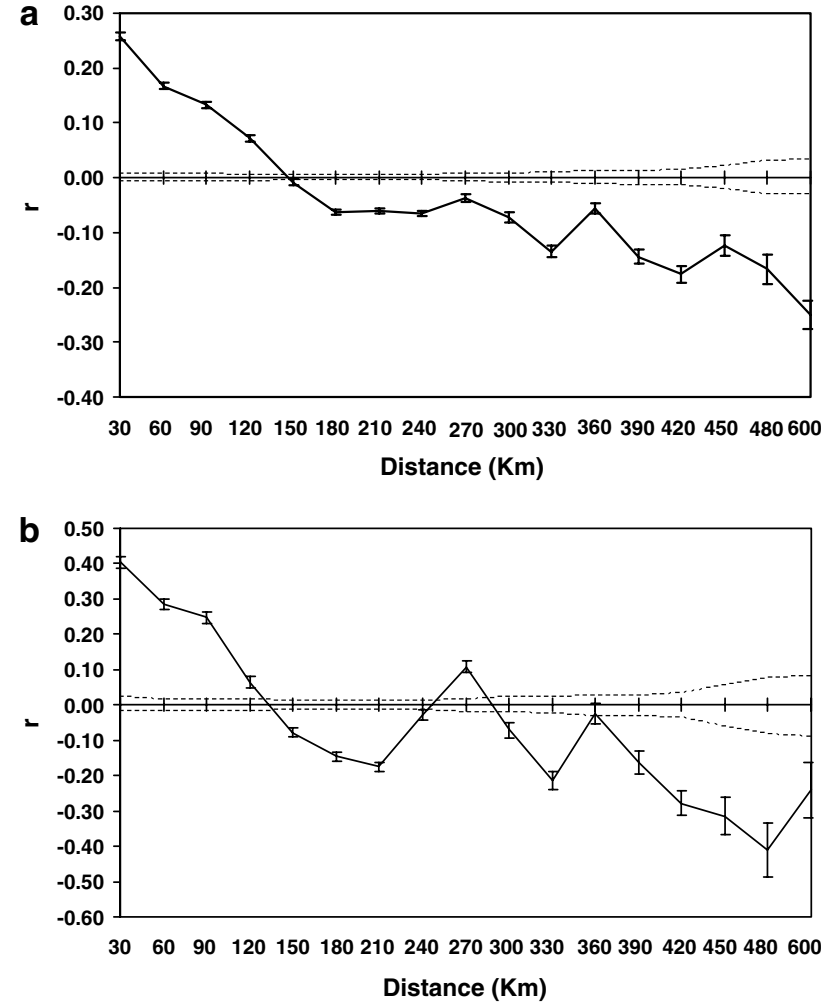

Figure 3 Correlograms of the genetic correlation coefficient $r$ as a function of distance for all pairwise comparisons of Brazilian peppertree individuals sampled across Florida $(N=592)$ for (a) nuclear microsatellite loci and (b) cpDNA haplotypes. Dashed lines represent the permuted 95\% CI around the random expectation (i.e., genotypes are randomly distributed or $r=0$ ) and error bars represent the bootstrapped 95\% CIs around $r$ for each distance class. Sample sizes for each category averaged 10290 pairwise comparisons (range 581-22562).

had stronger spatial dependence compared the western haplotype, which is also evident in its more patchy distribution especially in the more northern parts of the tree's distribution (Figures 5 and 6). Cross-validation analysis of these models predicted the occurrence of each haplotype reasonably well given the relatively low sampling density across the state (eastern $y=0.88$ $\left( \pm 0.07\right.$ s.e. $x+0.08, R^{2}=0.43$; western $y=0.95( \pm 0.08$ s.e.) $x+0.02, R^{2}=0.39$ ). The spatial interpolation maps for the cpDNA haplotypes revealed that the highest area of occurrence for each type coincided with their respective introduction points (Figures 5 and 6). Both maps revealed a general clinal pattern extending from southeast to northwest Florida. The eastern haplotype map revealed a more complex spatial distribution in the northern part of the range with patches of high and low occurrence (Figure 5). A patch of relatively high occurrence (0.6-0.8) occurred in the northwest at the limits of the species' range in Florida, and there also was a patch of very low occurrence (0-0.2) in the northeastern portion of the range. The western haplotype, on the other hand, revealed a more even clinal pattern across the state with a few small patches of high occurrence (0.8-1.0) occurring away from the original introduction point (Punta Gorda) from the southwest to northeast (Figure 6). The spatial interpolation maps suggest that the western 


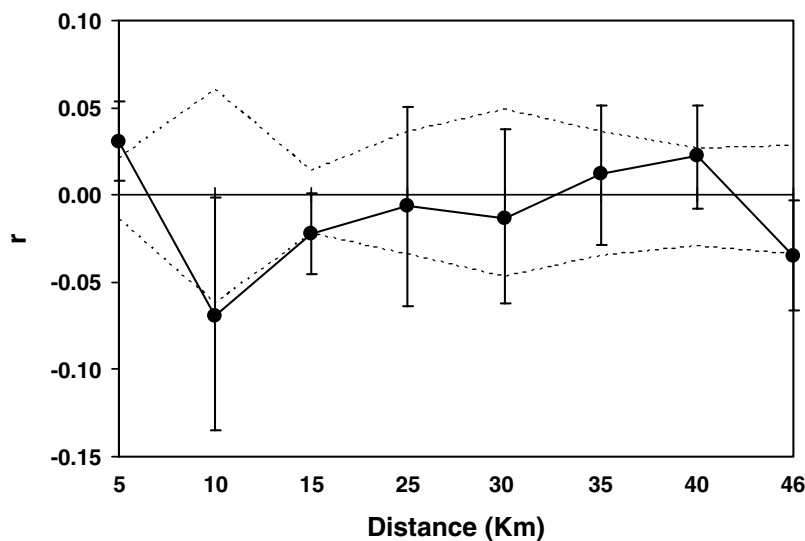

Figure 4 Correlogram of the genetic correlation coefficient $r$ as a function of distance for all pairwise comparisons of Brazilian peppertrees sampled in Miami-Dade County $(N=83)$ for nuclear microsatellite loci. Dashed lines represent the permuted 95\% CI around the random expectation (i.e., genotypes are randomly distributed or $r=0$ ) and error bars represent the bootstrapped 95\% CIs around $r$ for each distance class. Sample sizes for each category averaged 425 pairwise comparisons (range 106-959). haplotype had a relatively high probability of occurrence (0.6-1.0) in an area covering approximately $43500 \mathrm{~km}^{2}$ in the northern part of the plants range, whereas the eastern haplotype had a relatively high probability of occurrence over a smaller area $\left(\sim 25300 \mathrm{~km}^{2}\right)$ in the southern part of the state.

The Gaussian semivariogram model for spatial correlation best fit the spatial distribution of the coefficient of eastern ancestry $(q)$ as inferred from the nuclear microsatellite loci (Table 1). Cross validation of the coefficient of eastern ancestry $(y=0.96( \pm 0.04$ s.e. $) x+$ $\left.0.02, R^{2}=0.56\right)$ was slightly better than for either of the cpDNA haplotypes. The spatial pattern for the proportion $(q)$ of eastern ancestry calculated from the nuclear microsatellite data was positively correlated with the spatial pattern for the eastern cpDNA haplotype $(r=0.90)$ and negatively correlated with the western cpDNA haplotype $(r=-0.97)$ (Figure 7$)$. Areas of high ancestry surrounded each original introduction point and there was a general southeast to northwest cline. As in the spatial distributions for the cpDNA haplotypes, there was evidence for long-distance pioneering patches from each introduction in the northern part of the

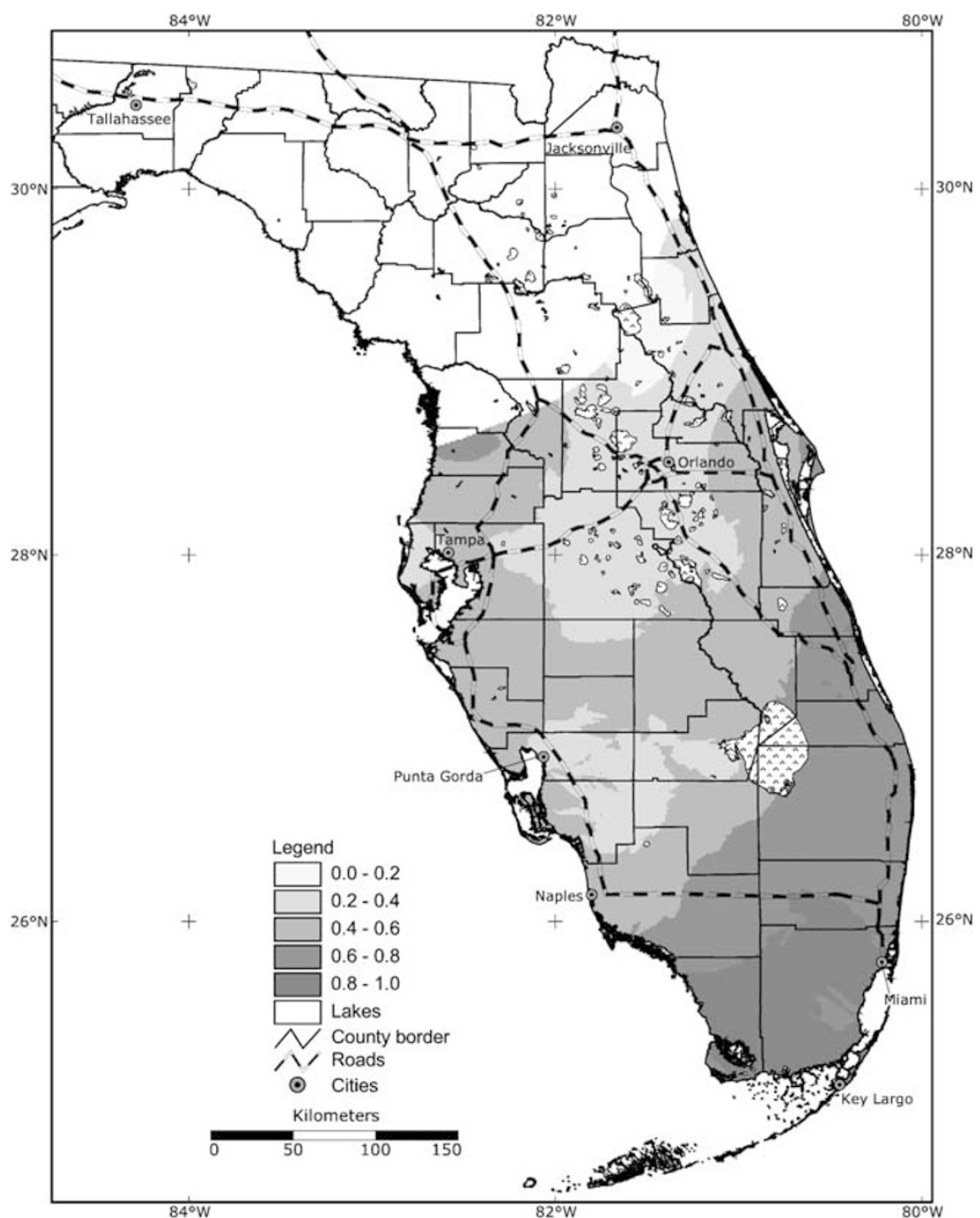

Figure 5 Eastern haplotype surface obtained by spatial interpolation (kriging) using the variogram model reported in Table 1. Categories refer to the likelihood that this haplotype will occur in a specific geographic locality. 


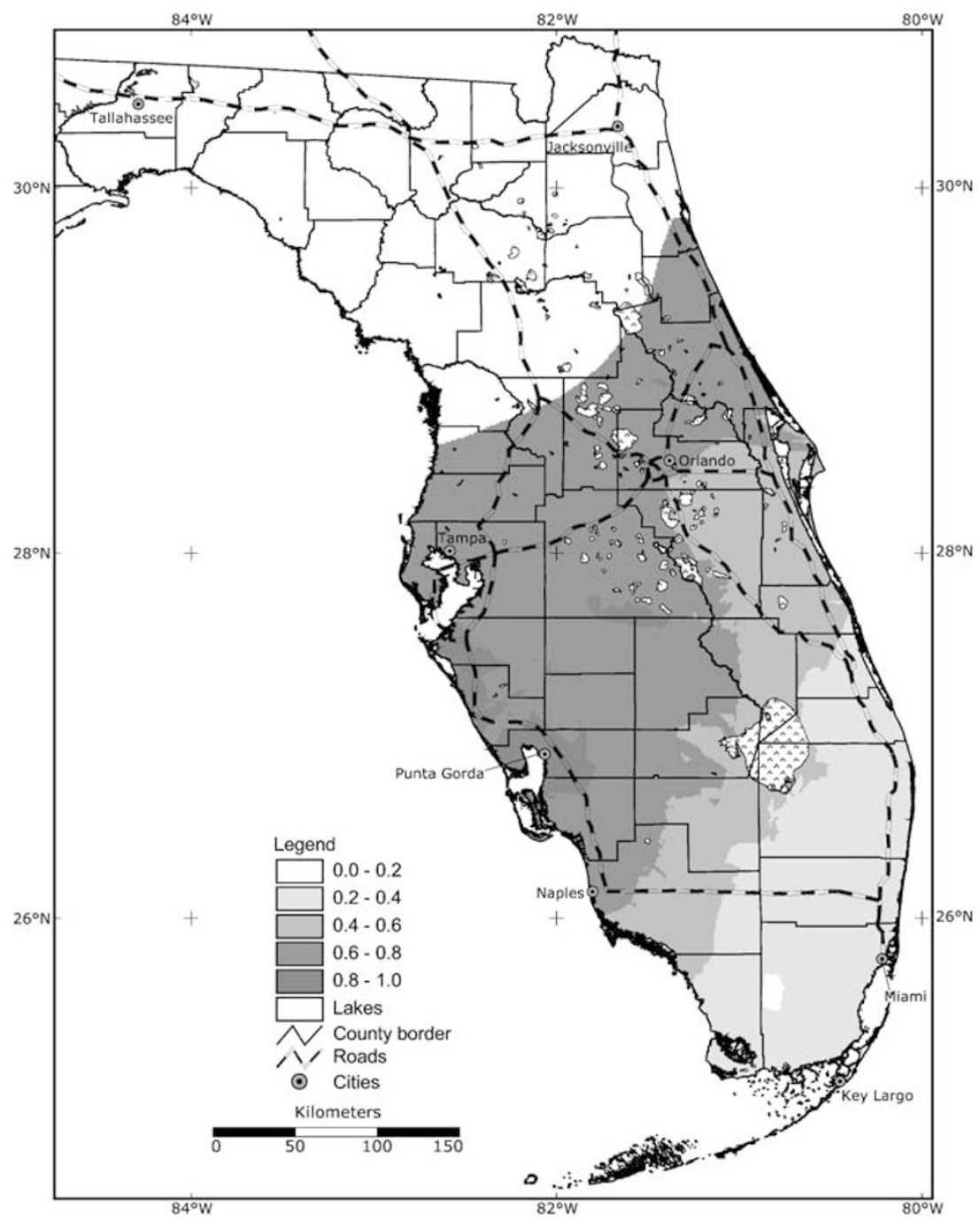

Figure 6 Western haplotype surface obtained by spatial interpolation (kriging) using the variogram model reported in Table 1. Categories refer to the likelihood that this haplotype will occur in a specific geographic locality.

Table 1 Variogram models used in the construction of interpolated maps for the genetic spatial structure of Brazilian peppertree across the state of Florida, USA

\begin{tabular}{lcccccrr}
\hline & $N$ & Model type & Nugget & Sill & Nugget/sill \% & Range $(\mathrm{km})$ & $R^{2}$ \\
\hline Eastern cpDNA & 237 & Gaussian & 0.012 & 0.066 & 18.2 & 167.7 & 0.84 \\
Western cpDNA & 242 & Gaussian & 0.040 & 0.102 & 39.2 & 288.6 \\
Eastern ancestry $(q)$ & 479 & Gaussian & 0.028 & 0.119 & 23.5 & 0.96 \\
\hline
\end{tabular}

Abbreviation: CPDNA, chloroplast DNA.

Models for the eastern and western cpDNA haplotypes and the coefficient of eastern ancestry $(q)$ inferred from nuclear microsatellite loci are presented.

species' range in Florida. Patches of high western ancestry $(q=0.80-1.0)$ occurred in a southwest to northeast direction and there was evidence for past longdistance movements of the eastern haplotype in the several large patches of hybrids $(q=0.4-0.6)$ in the extreme northwest portion of the species' range.

\section{Discussion}

The current spatial genetic structure of Brazilian peppertree in Florida supports a pattern of stratified dispersal that is similar to patterns generated both by theoretical models and empirical studies of colonization during range expansion and secondary contact between genetically distinct populations (Nichols and Hewitt, 1994; Ibrahim et al., 1996; Le Corre et al., 1998). Both the cpDNA and nuclear microsatellite data revealed a clear genetic cline from Miami to Punta Gorda that has arisen from the two introductions making contact with each other and hybridizing as they spread outward. Statewide spatial autocorrelation placed the point of contact between the two introduction cities at $\sim 147 \mathrm{~km}$.

While humans created long-distance pioneering populations of this plant in towns throughout the state, 


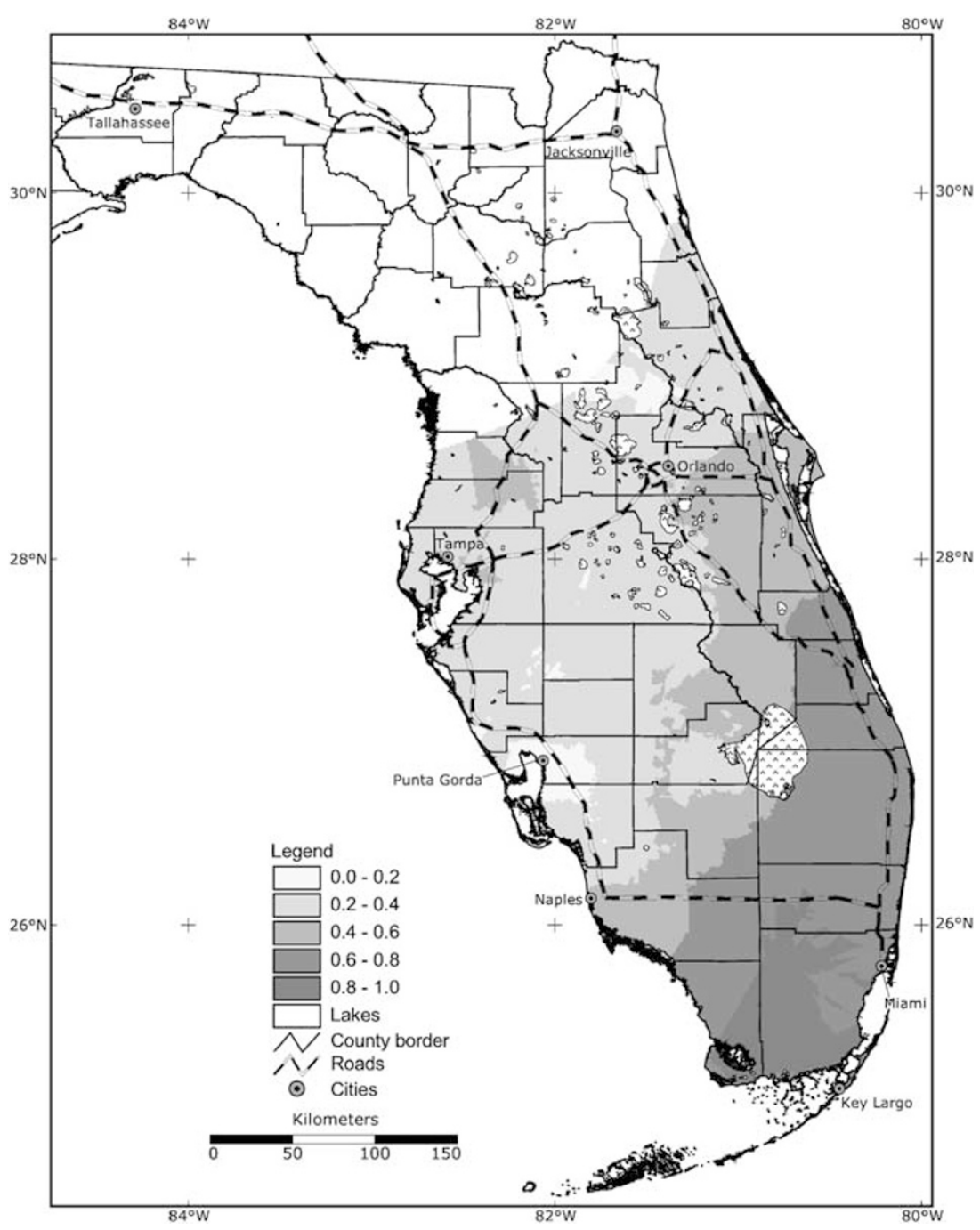

Figure 7 Coefficient of eastern ancestry $(q)$ surface obtained by spatial interpolation (kriging) using the variogram model reported in Table 1 . Categories refer to the proportion of eastern ancestry (inferred from nuclear microsatellite loci) of individuals found in a given locality. The proportion of western ancestry for these same areas is simply $1-q$.

the spread of Brazilian peppertree from these towns presumably occurred primarily through animal dispersal. Both cpDNA haplotypes were found at large distances $(>100 \mathrm{~km})$ from their original introduction points and wide bands composed predominantly of hybrid individuals extended from east to west across the state, suggesting that both introductions were moved long distances across the state. Patches of relatively high and low occurrence for both cpDNA haplotypes and for the proportion of eastern ancestry coefficient $(q)$ were evident in the northern part of Brazilian peppertree's range in Florida. This suggests that in the past, humans transported both eastern and western plants to the northern limits of the species range. Diffusive dispersal and short-distance pioneering events were evident by the presence of large patches around the introduction sites that still retain high ancestry values of their respective introductions and the clinal pattern with non-overlapping confidence intervals at progressively greater distance categories. The pattern of positive spatial autocorrelation at only the shortest distance class $(5 \mathrm{~km})$ in both northern Florida and in Miami-Dade County in the southeast was also indicative of short- distance dispersal (Epperson, 2003; Hardy and Vekemans, 1999).

In this study, the proportions of eastern and western haplotypes were very similar (49\% eastern and 51\% western); however, in Williams et al. (2005), we reported these haplotypes at 40 and $60 \%$, respectively. The discrepancy between the two studies arose because of our greater sampling effort in Miami-Dade County increased the proportion of the eastern haplotype in this study. Removing these samples resulted in proportions that were more similar to the original study ( $44 \%$ eastern and $56 \%$ western). Removal of these samples, however, did not change any of the results for the variogram models or large-scale genetic spatial autocorrelation (results not presented). These results suggest that western haplotype individuals are more common in the state than eastern haplotype individuals, a finding which is also consistent with the larger spatial area over which there is a high probability of occurrence for the western haplotype. Humans may have moved the western introduction over a larger area in the central and northern part of the present-day range. Past patterns of diffusive spread, although, seem to have been very 
similar for both cpDNA haplotypes as evidenced by the similar decrease in abundance with distance from the original introduction points and the same pattern of short distance positive spatial autocorrelation in the north and south.

The Brazilian peppertree was not noticed outside of cultivation until over 50 years following its introduction. Lag periods are expected in the early phases of population growth owing to small numbers of individuals and limited dispersal, but they also may occur because the introduced species is undergoing a period of adaptation or hybridization that then allows it to spread rapidly in its new habitat (Sakai et al., 2001). Hybridization can potentially facilitate invasiveness by increasing genetic variation and giving rise to novel genotypes that may be selectively advantageous in the new range (Ellstrand and Schierenbeck, 2000; Kolbe et al., 2004; Facon et al., 2005). Our data revealed that varying degrees of intraspecific hybrids cover most of the current range of Brazilian peppertree in Florida. Whether hybridization or simply stratified dispersal facilitated the plants spread outside of cultivation is difficult to disentangle in this particular instance. Stratified dispersal and hybridization could act in concert to increase the rate and extent of spread of invasive species. Stratified dispersal increases the rate of spread relative to simple diffusion dispersal (Higgins and Richardson, 1999; Novak and Mack, 2001; Suarez et al., 2001); however, it is also expected to increase the chance that spatially separated populations from different source origins will come into secondary contact and hybridize. Reciprocal transplant experiments between Florida and the native source regions will be necessary to address the question of whether hybrids are relatively more fit in Florida than pure breeds.

Legislative action in 1990 has made it illegal to transport, plant, and sell this invasive species throughout most of the state. It is likely that long-distance dispersal through human transport is probably not as common today as it was in the past. Still, the extensive areas of hybridization across the state and the fact that our samples contained very few trees that were obviously planted for ornamental purposes indicate that Brazilian peppertree is dispersed extensively by animal vectors. Future efforts at managing this species will need to take dispersal by animals into consideration because it suggests that Brazilian peppertree will be able to quickly recolonize areas from which it is extirpated. Under these circumstances, ecological theory suggests that effective management may require releasing a natural enemy that also can disperse widely in order to effectively track its host (Fagan et al., 2002). However, if biocontrol agents with low dispersal capabilities are utilized, then release of many small populations over the entire range in Florida may be required. The extensive areas of hybridization across the state also may have implications for the efficiency of the biocontrol agents. Herbivores can be closely coadapted to a specific genotype of a host, and so collecting biocontrol agents in the source region of the pest species may both increase specificity of the control agent and make it more likely that they will inflict significant damage (e.g., Goolsby et al., 2006). The fact that much of Florida is now composed of hybrids means that it will not be possible to find a single closely coadapted control agent, as it is likely that the source regions in South America are distantly separated and unlikely to hybridize naturally (Williams et al., 2005). Currently, plant/herbivore compatibility of all candidate biocontrol agents in quarantine (Cuda et al., 2004; Martin et al., 2004; Cuda et al., 2005) are or will be tested on Brazilian peppertree individuals that still retain high ancestry for their respective introductions and on various categories of hybrid individuals. If there is a differential response of these agents to the genotype of the plant, then the genetic maps we have constructed for Florida could also be useful for selecting release sites with the most compatible Brazilian peppertree genotypes, and for predicting spatial effectiveness of different agents.

\section{Acknowledgements}

We thank the many organizations and individuals who helped to collect samples: UF-IFAS Cooperative Extension Service: Kenneth Gioeli - St Lucie Co.; Dan Culbert Okeechobee Co.; John Alleyne - Pinellas Co.; John Brenneman - Polk Co.; Kim Gabel - Monroe Co.; Melissa Henning - Collier Co.; Gene McAvoy - Hendry Co.; Adrian Hunsberger - Miami-Dade Co.; Brian Suber Seminole Co.; Mike Ray - Seminole Co.; D Vanderbleek Lake Co.; Anne Schmidt - Pasco Co.; Sheryl Bowman Pasco Co.; Southwest Florida Water Management District: Kenny Smith, Mack Sweat, Martin Co. Parks and Recreation: Steve McGuffey; National Park Service: Tony Pernas; Others: James Boggs, Sharon Ewe, Mac Hatcher, Markus Henning, Veronica Manrique, Frank Melton, Liberta Scotto, Jason Seitz, and Greg Wheeler. Amanda Hale and two anonymous reviewers provided helpful comments on the manuscript. Our work has been supported by the University of Miami, University of Florida, and the Florida Exotic Pest Plant Council.

\section{References}

Baker HG (1974). The evolution of weeds. Ann Rev Ecol Syst 5: $1-24$.

Cuda JP, Habeck DH, Hight SD, Medal JC, Pedrosa-Macedo JH (2004). Brazilian peppertree, Schinus terebinthifolius: Sumac family-Anacardiaceae. In: Coombs E, Clark J, Piper G, Cofrancesco A (eds). Biological Control of Invasive Plants in the United States. Oregon State University Press: Corvallis, Oregon. pp 439-441.

Cuda JP, Medal JC, Vitorino MD, Habeck DH (2005). Supplementary host specificity testing of the sawfly Heteroperryia hubrichi, a candidate for classical biological control of Brazilian peppertree, Schinus terebinthifolius, in the USA. Bio Control 50: 195-201.

Ellstrand NC, Schierenbeck KA (2000). Hybridization as a stimulus for the evolution of invasiveness in plants? Proc Nal Acad Sci USA 97: 7043-7050.

Epperson BK (2003). Geographical Genetics. Princeton University Press: Princeton, New Jersey.

Ewel JJ (1986). Invasibility: lessons from south Florida. In: Mooney HA, Drake JA (eds). Ecology of Biological Invasions of North America and Hawaii. Springer-Verlag: New York. pp 214-230.

Ewel JJ, Ojima DS, Karl DA, DeBusk WF (1982). Schinus in successional ecosystems of Everglades National Park. South Florida Research Report, T-676. Everglades National Park.

Facon B, Jarne P, Pointier JP, David P (2005). Hybridization and invasiveness in the freshwater snail Melanoides tuberculata: hybrid vigour is more important than increase in genetic variance. J Evol Biol 18: 524-535. 
Fagan WF, Lewis MA, Neubert MG, van den Driessche P (2002). Invasion theory and biological control. Ecol Lett 5: 148-157.

Ferriter A (ed) (1997). Brazilian Peppertree Management Plan for Florida. Florida Exotic Pest Plant Council, Brazilian Peppertree Task Force: Florida.

Goolsby JA, De Barro PJ, Makinson JR, Pemberton RW, Hartley DM, Frohlich DR (2006). Matching the origin of an invasive weed for selection of a herbivore haplotype for a biological control programme. Mol Ecol 15: 287-297.

Hamilton MB (1999). Four primers for the amplification of chloroplast intergenic regions with intraspecific variation. Mol Ecol 8: 521-523.

Hampton JO, Spencer PBS, Alpers DL, Twigg LE, Woolnough $\mathrm{AP}$, Doust J et al. (2004). Molecular techniques, wildlife management and the importance of genetic population structure and dispersal: a case study with feral pigs. J App Ecol 41: 735-743.

Hardy OJ, Vekemans X (1999). Isolation by distance in a continuous population: reconciliation between spatial autocorrelation analysis and population genetics models. Heredity 83: $145-154$.

Hastings A, Cuddington K, Davies KF, Dugaw CJ, Elmendorf S, Freestone A et al. (2005). The spatial spread of invasions: new developments in theory and evidence. Ecol Lett 8: 91-101.

Hengeveld R (1989). Dynamics of Biological Invasions. Chapman and Hall: New York, New York.

Higgins SI, Richardson DM (1999). Predicting plant migration rates in a changing world: the role of long-distance dispersal. Am Nat 153: 464-475.

Ibrahim KM, Nichols RA, Hewitt GM (1996). Spatial patterns of genetic variation generated by different forms of dispersal during range expansion. Heredity 77: 282-291.

Johansen AD, Latta RG (2003). Mitochondrial haplotype distribution, seed dispersal and patterns of postglacial expansion of ponderosa pine. Mol Ecol 12: 293-298.

Kolbe JJ, Glor RE, Schettino LR, Lara AC, Larson A, Losos JB (2004). Genetic variation increases during biological invasion by a Cuban lizard. Nature 431: 177-181.

Le Corre V, Roussel G, Zanetto A, Kremer A (1998). Geographical structure of gene diversity in Quercus petraea (Matt.) Liebl. III. Patterns of variation identified by geostatistical analyses. Heredity 80: 464-473.

Mandon-Dalger I, Clergeau P, Tassin J, Riviere JN, Gatti S (2004). Relationships between alien plants and an alien bird species on Reunion Island. J Trop Ecol 20: 635-642.

Martin CG, Cuda JP, Awadzi KD, Medal JC, Habeck DH, Pedrosa-Macedo JH (2004). Biology and laboratory rearing of Episimus utilis (Lepidoptera: Tortricidae), a candidate for classical biological control of Brazilian peppertree, Schinus terebinthifolius (Anacardiaceae) in Florida. Environ Ento 33: 1351-1361.
Moody ME, Mack RN (1988). Controlling the spread of plant invasions - the importance of nascent foci. J Appl Ecol 25: 1009-1021.

Morton JF (1978). Brazilian peppertree - its impact on people, animals and the environment. Econ Bot 32: 353-359.

Nichols RA, Hewitt GM (1994). The genetic consequences of long-distance dispersal during colonization. Heredity $\mathbf{7 2}$ 312-317.

Novak SJ, Mack RN (2001). Tracing plant introduction and spread: genetic evidence from Bromus tectorum (Cheatgrass). Bioscience 51: 114-122.

Panetta FD, McKee J (1997). Recruitment of the invasive ornamental, Schinus terebinthifolius, is dependent upon frugivores. Aust J Ecol 22: 432-438.

Peakall R, Smouse PE (2005). GenAlEx 6: Genetic Analysis in Excel. Population Genetic Software for Teaching and Research. Australian National University: Canberra, Australia. http:// www.anu.edu.au?BoZo/GenAlEx/.

Petit RJ, Bialozyt R, Garnier-Géré P, Hampe A (2004). Ecology and genetics of tree invasions: from recent introductions to Quaternary migrations. For Ecol Manage 197: 117-137.

Pritchard JK, Stephens M, Donnelly P (2000). Inference of population structure using multilocus genotype data. Genetics 155: 945-959.

Pritchard JK, Wen W (2003). Documentation for Structure Software: Version 2. Available at: http://pritch.bsd.uchicago.edu.

Robertson BC, Gemmell NJ (2004). Defining eradication units to control invasive pests. J Appl Ecol 41: 1042-1048.

Sakai AK, Allendorf FW, Holt JS, Lodge DM, Molofsky J, With KA et al. (2001). The population biology of invasive species. Ann Rev Ecol Syst 32: 305-332.

Schmitz DC, Simberloff D, Hofstetter RH, Haller W, Sutton D (1997). The ecological impact of nonindigenous species. In: Simberloff D, Schmitz DC, Brown TC (eds). Strangers in Paradise: Impact and Management of Nonindigenous Species in Florida. Island Press: Washington, DC. pp 9-61.

Smouse PE, Peakall R (1999). Spatial autocorrelation analysis of individual multiallele and multilocus genetic structure. Heredity 82: 561-573.

Suarez AV, Holway DA, Case TJ (2001). Patterns of spread in biological invasions dominated by long-distance jump dispersal: insights from Argentine ants. Proc Natl Acad Sci USA 98: 1095-1100.

Williams DA, Overholt WA, Cuda JP, Hughes CR (2005). Chloroplast and microsatellite DNA diversities reveal the introduction history of Brazilian peppertree (Schinus terebinthifolius) in Florida. Mol Ecol 14: 3643-3656.

Williams DA, Sternberg L da SL, Hughes CR (2002). Characterization of polymorphic microsatellite loci in the invasive Brazilian peppertree, Schinus terebinthifolius. Mol Ecol Notes 2: 231-232. 